\title{
Noxa Is a Critical Mediator of p53-Dependent Motor Neuron Death after Nerve Injury in Adult Mouse
}

\author{
Sumiko Kiryu-Seo, ${ }^{1}$ Teruhisa Hirayama, ${ }^{1,2}$ Ryuichi Kato, ${ }^{1,3}$ and Hiroshi Kiyama ${ }^{1}$ \\ ${ }^{1}$ Department of Anatomy and Neurobiology, Graduate School of Medicine, Osaka City University, Osaka 545-8585, Japan, ${ }^{2}$ Department of Orthopedic \\ Surgery, Asahikawa Medical College, Asahikawa 078-8510, Japan, and 3 Department of Urology, Sapporo Medical University, Sapporo 060-8543, Japan
}

\begin{abstract}
Axotomy-induced motor neuron death occurs within a week in the neonatal rat and mouse. However, slowly progressive motor neuron death, which takes more than a month, occurs after axotomy in the adult mouse (C57BL/6) but not in the adult rat (Wistar). Here we demonstrate that expression of a p53-inducible Bcl-2 homology domain 3 (BH3)-only protein, Noxa, is enhanced in axotomized neurons of the adult mouse but not in the adult rat. In p53-deficient mice, slowly progressive neuronal death was suppressed and accompanied by reduced Noxa expression after axotomy. However, a minor response of Noxa expression was still observed after axotomy in p53-deficient mice, suggesting that p53-independent Noxa expression occurs to a minor extent. Noxa-deficient mice were used to confirm the consequence of Noxa expression in nerve-injured mouse motor neurons. In Noxa-deficient mice, axotomy-induced motor neuron death was suppressed. Furthermore, among the BH3-only protein members examined, Noxa exhibited the most marked upregulation after axotomy in the mouse. In conclusion, motor neuron death seen in the adult mouse is mainly p53 dependent, and Noxa is a major executor for axotomy-induced motor neuron death in the adult mouse, as a mediator located downstream of p53.
\end{abstract}

Key words: Noxa; BH3-only protein; nerve injury; motor neuron; axotomy; neuronal death

\section{Introduction}

Rats and mice are concordant animals, and most of their genotypes and phenotypes can be considered similar. However, we observed that this is not the case for motor neuron regeneration. Nerve-injured motor neurons of the adult rat can survive, whereas similar axotomy leads to gradual cell death of the injured motor neurons in the adult mouse. Motor neuron death seen in the adult mouse progresses much slower than that seen in the neonatal mouse and rat (Snider et al., 1992) (S. Kiryu-Seo and H. Kiyama, unpublished data). Therefore, the cell death seen in the adult mouse could be a more appropriate model for neurodegenerative diseases such as amyotrophic lateral sclerosis than the cell death seen in neonates. Because several studies highlighted that the tumor suppressor p53 is activated in damaged neurons and that subsequent caspase- 3 activation occurs in a model of CNS injury such as focal ischemia, kainate excitotoxicity, and peripheral nerve injury (Miller et al., 2000; Morrison and Kinoshita, 2000; Martin and Liu, 2002), the slow progressive motor neuron death after axotomy, which is seen in the adult mouse, is also likely to be triggered by a p53-dependent mechanism. However,

Received Sept. 29, 2004; revised Dec. 16, 2004; accepted Dec. 18, 2004.

This work was supported in part by grants from the Ministry of Health, Labor, and Welfare of Japan; the Ministry of Education, Science, Technology, Sports, and Culture; and the Japan Science and Technology Corporation. We thank Chiho Kadono for excellent technical assistance and Emiko Fukui for secretarial assistance. We thank Drs. Tadatsugu Taniguchi and Tsukasa Shibue (Tokyo University, Tokyo, Japan) for providing Noxa knock-out mice and Noxa antibody and Dr. Bert Vogelstein (Johns Hopkins University, Baltimore, MD) for providing Puma plasmid.

Correspondence should be addressed to Dr. Hiroshi Kiyama, Department of Anatomy and Neurobiology, Graduate School of Medicine, Osaka City University, 1-4-3 Asahimachi, Abeno-ku, Osaka 545-8585, Japan. E-mail: kiyama@med.osaka-cu.ac.jp.

DOI:10.1523/JNEUROSCI.4041-04.2005

Copyright $\odot 2005$ Society for Neuroscience $\quad$ 0270-6474/05/251442-06\$15.00/0 the linkage between p53 and activation of the caspase cascade is still elusive, at least in motor neuron death in the adult mouse.

In general, p53 regulates cellular responses to stress through transcriptional regulation of genes such as Bax, p21 WAF1, and MDM2 (Vousden and Lu, 2002). Apoptosis stimulated by 553 was associated with disturbance of mitochondrial membrane potential, accumulation of reactive oxygen species, stimulation of caspase-9, and subsequent activation of the caspase cascade. In this context, several p53-transactivated target genes have been proposed to mediate apoptosis, although transcriptionindependent activities of p53 have been described recently (Baptiste and Prives, 2004). Among those p53 targets, mitochondrial proteins are particularly attractive, because p53-dependent apoptosis is mainly elicited through a mitochondria-mediated pathway (Polyak et al., 1997). The proapoptotic protein Bax is the most characterized and well established molecule as a mediator for the mitochondria-mediated apoptotic cascade (Miyashita and Reed, 1995). Motor neurons in Bax-deficient neonatal mice fail to degenerate after axotomy, and it was concluded that trophic factor deprivation-induced death of motor neurons is dependent on Bax (Deckwerth et al., 1996). In this respect, Bax could be a major death executor located downstream of p53 in the neonate. However, recently, other p53-inducible target genes, Noxa and Puma, have been identified (Oda et al., 2000; Nakano and Vousden, 2001). They belong to one of the Bcl-2 family proteins, Bcl-2 homology domain 3 (BH3)-only proteins, which are crucial death regulators that reside immediately upstream of the mitochondria and induce mitochondrial dysfunction (Seo et al., 2003), although their implications in nerve injury-induced motor neuron death are unknown. In this paper, we demonstrate 
that the p53-mediated death pathway contributes to progressive motor neuron death in the adult mouse and that Noxa is a critical mediator of the p53-mediated death pathway in the adult mouse.

\section{Materials and Methods}

Animals. Seven-week-old male C57BL/6 mice $(n=140)$ and Wistar rats $(n=62)$ were anesthetized with pentobarbital $(45 \mathrm{mg} / \mathrm{kg}$, i.p.) and positioned supine; their right hypoglossal nerve was then cut with scissors. Homozygous p53-deficient mice $(n=48)$ were purchased from The Jackson Laboratory (Bar Harbor, ME). Noxa-deficient mice $(n=15)$ were established by Dr. T. Taniguchi and colleagues (Tokyo University, Tokyo, Japan) (Shibue et al., 2003). All mouse strains had an inbred C57BL/6 genetic background or had been backcrossed at least five times. All experiments were performed in compliance with institutional guidelines.

Histology. Animals were decapitated 1, 3, 7, 28, 35, and $56 \mathrm{~d}$ after the operation (eight animals at each point), and brains were removed quickly and frozen in powdered dry ice. Next, $18-\mu \mathrm{m}$-thick sections were cut on a cryostat, thaw-mounted onto 3-aminopropyltriethoxysilane-coated slides, and stored at $-80^{\circ} \mathrm{C}$ until use. The level of hypoglossal nucleus was serially sectioned, and every fifth section was attached on the same group of slides. The adjacent section was attached on the slide for the next group, and accordingly, five groups of slides from one animal were prepared. Cell counts were done blind as to the treatment condition using a well established counting method that effectively eliminates the possibility of counting the same cell twice (Clarke and Oppenheim, 1995). According to the literature, the following criteria were used for the counting: large soma, a clear nucleus with intact nuclear membrane, and at least one large clump of nucleolar material. For quantification of motor neuron survival after unilateral axotomy, thionine-stained hypoglossal motor neurons in injured and control sides were counted separately in every fifth section of each animal examined. The counts were done using three independent groups of slides per animal. Data were presented as the percentage of surviving neurons on the injured and control side. Statistical significance ( $p$ value) was calculated by two-tailed Student's $t$ test. As for the comparison of total number of motor neurons between the knock-out ( $\mathrm{Noxa}^{-/-}$and $\mathrm{p}^{-3^{-/-}}$) and the wild-type mice, motor neurons were counted following the criteria at the identical level between animals in every fifth section of the population examined, and the raw count of motor neurons was multiplied by five to give an estimate of total cell numbers and corrected with a correction factor that took into account the thickness of the section and the average nucleolar diameters (Abercrombie, 1946).

All procedures for in situ hybridization were performed as described previously (Kiryu et al., 1995). The fragments amplified by PCR (supplemental material, available at www.jneurosci.org) using cDNA isolated from rats and mice were inserted into pGEM-T Easy vector (Promega, Madison, WI) and used as probes. Data are representative of three independent experiments using at least seven animals.

Western blotting. Samples were collected from control and operated hypoglossal nuclei of 10 mice at $7 \mathrm{~d}$ after axotomy and homogenized in lysis buffer (20 mм HEPES, pH 7.4, $120 \mathrm{~mm} \mathrm{NaCl,} 5$ mм EDTA, 1\% Triton X-100, 10\% glycerol, $5 \mu \mathrm{g} / \mathrm{ml}$ aporotinin, $1 \mathrm{~mm}$ PMSF, and 1 $\mu \mathrm{g} / \mathrm{ml}$ leupeptin). The homogenate was centrifuged at $4^{\circ} \mathrm{C}$ for $15 \mathrm{~min}$ at $15,000 \mathrm{rpm}$. The supernatant $(50 \mu \mathrm{g})$ was loaded and immunoblotted with anti-Noxa antibody (generously provided by Dr. Taniguchi and colleagues, Tokyo University) and anti-glyceraldehyde-3-phospate dehydrogenase (GAPDH) antibody (Ambion, Austin, TX).

Reverse transcription-PCR analysis. For details of the reverse transcription (RT)-PCR method, see the supplemental material (available at www.jneurosci.org). Quantification was performed using an image scanner (GT-8200UF; Epson) and image analysis software (Photoshop 6.0; Adobe Systems, San Jose, CA). The density was measured at five points for each band and normalized against that of GAPDH. The magnitude of the change in relative transcriptional level was expressed as operated side/control side. Statistical significance of differences was assessed by ANOVA followed by Fisher's PLSD test.

\section{Results}

\section{Axotomized motor neurons have different fates in rats and mice}

We first assessed how the fate of injured motor neurons differs between the Wistar rat and C57BL/6 mouse (Fig. $1 A-C$ ). At $\sim 2$ months after hypoglossal nerve injury, adult C57BL/6 mice displayed extensive loss of motor neurons compared with Wistar rats. In both rats and mice, the number of surviving motor neurons in the hypoglossal nuclei showed no change at $7 \mathrm{~d}$ after nerve injury. However, from that time on, the number of surviving motor neurons in mice gradually decreased, whereas that in rats showed no change. At 8 weeks after nerve injury, only $20 \%$ of injured motor neurons of mice survived, whereas almost all motor neurons of rats survived.

Next, we explored the molecular basis of this difference. In our previous molecular screening work using differential display, random cloning, and DNA microarray, we identified a collection of rat genes, the expression of which was upregulated after rat hypoglossal nerve transection (Kiryu et al., 1995; Tanabe et al., 1999). We therefore subcloned those gene fragments from a mouse brain cDNA library by RT-PCR. Using these obtained mouse cDNA fragments, we examined whether the gene response pattern was identical between rats and mice by in situ hybridization. Although neuronal death seen in mice progressed slowly over weeks, all of the injured neurons still survived and did not demonstrate any morphological changes at $7 \mathrm{~d}$ after axotomy. At this time point, almost all of the genes examined, including major survival signal-associated genes [for instance, glial cell linederived neurotrophic factor receptors (GFR- $\alpha 1$ and c-Ret) (Honma et al., 2002), Akt, and Erk] showed a similar response pattern in rats and mice after axotomy (Fig. $1 D$ ). This suggests that antiapoptotic or defensive mechanisms seem to function in the adult mouse as well as the adult rat. This histological screening further demonstrated that axotomized motor neurons in both the adult rat and mouse showed enhanced mRNA expression of p53 transactivation genes such as Bax, MDM2, and p21 ${ }^{\mathrm{WAF}^{1}}$ (Fig. $1 E$ ), suggesting that p53 activation occurs in both rats and mice. However, a marked increase in Noxa, which is a $\mathrm{BH} 3$-only protein and a 53 target gene, was observed in mice but not in rats (Fig. $1 E$ ). The increase in Noxa protein was also observed in injured neurons of mice (Fig. $1 F$ ). In contrast, another p53 target gene, Puma, which is also a $\mathrm{BH} 3$-only protein, did not show any detectable mRNA signal in both rats and mice. This suggests that Noxa may be a molecule that is responsible for p53-mediated motor neuron death seen in the adult mouse, whereas the rat could somehow succeed in escaping from the cell death as a result of lack of Noxa expression.

\section{Noxa expression in response to nerve injury is suppressed in p53-deficient mice}

The above finding suggests that the slow motor neuron death seen in the adult mouse is p53 dependent and that Noxa is a possible mediator of p53-dependent death in the mouse. To elucidate the involvement of p53 in this slow death seen in mice, we compared the viability of hypoglossal motor neurons after axotomy between wild-type and $\mathrm{p} 53$-deficient $\left(\mathrm{p} 53^{-/-}\right)$mice. At 8 weeks after hypoglossal nerve injury, the number of surviving motor neurons in p53-deficient mice was apparently increased ( $\sim 80 \%$ were surviving), whereas $>80 \%$ of injured motor neurons disappeared in wild-type mice (Fig. $2 A, B$ ). The number of uninjured motor neurons was similar in both p53-deficient and wild-type mice (Fig. 2C). We then confirmed whether Noxa expression in response to nerve injury is changed in p53-deficient 
A

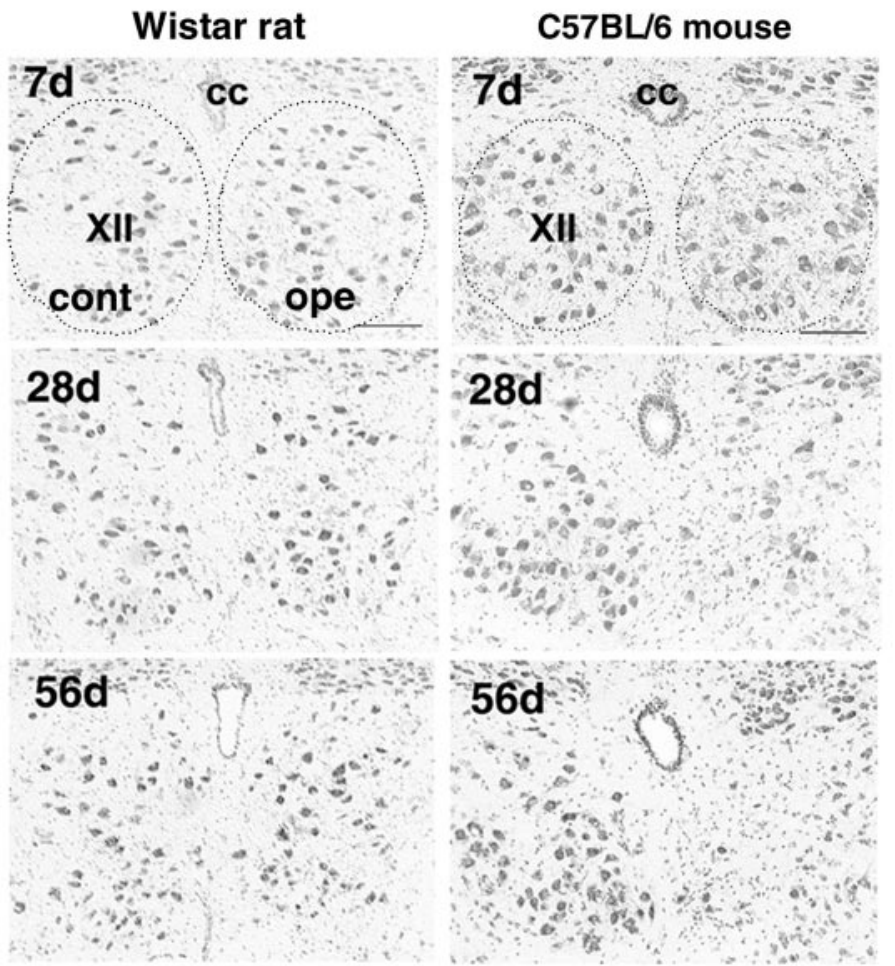

B

Wistar rat

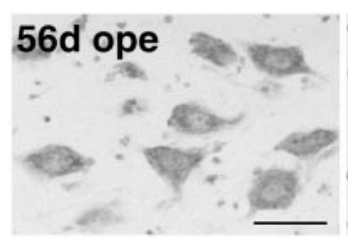

C

\section{C57BL/6 mouse}
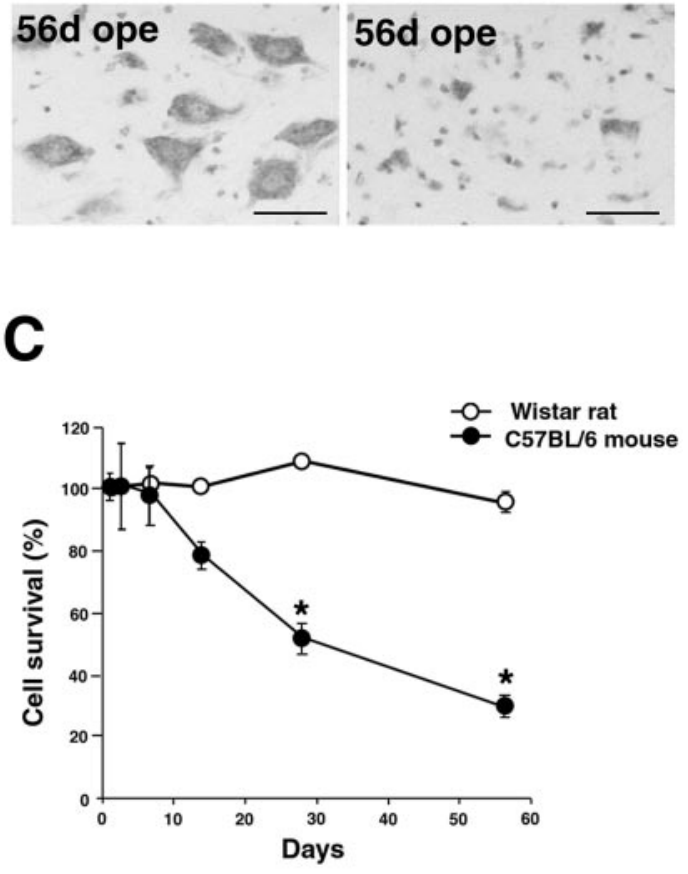

D
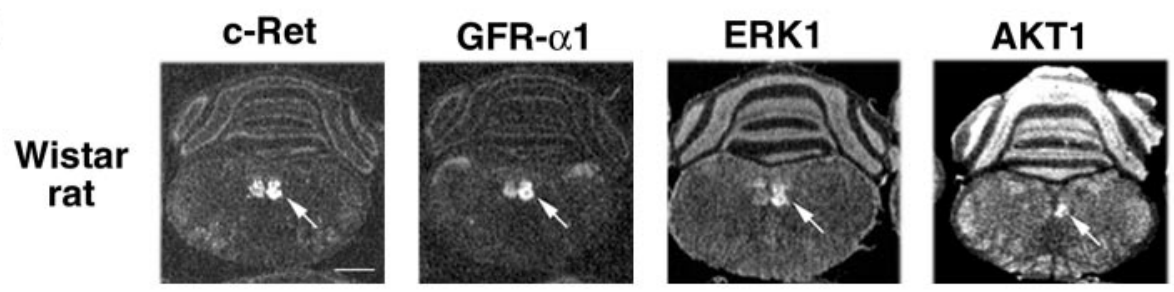

C57BL/6
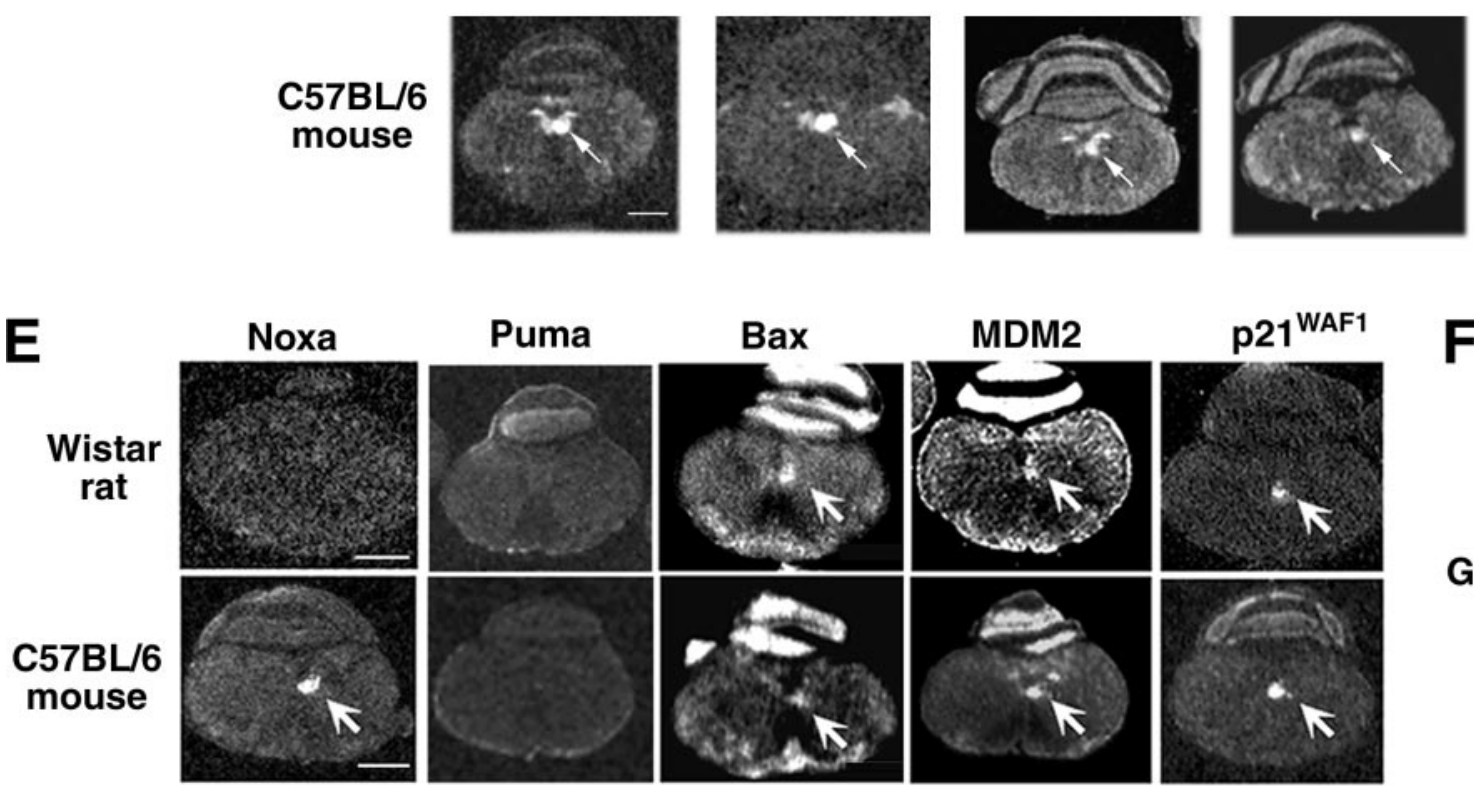

$F$

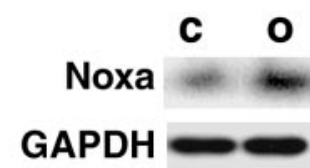

Figure 1. Differentfates of axotomized motorneurons in adult rats and mice. A, Thioninestaining of hypoglossal motor neurons. The hypoglossal nucleus is indicated shown by the dashed line. AdultC57BL/6 mice showed extensive motor neuron loss after hypoglossal nerve injury, whereas adult Wistar rats did not. cc, Central canal; XII, hypoglossal nucleus; cont, contralateral side; ope, operated side; Scale bars: left, $100 \mu \mathrm{m}$; right, $50 \mu \mathrm{m}$. B, High-power magnification of operated hypoglossal motor neurons in rats and mice $56 \mathrm{~d}$ after axotomy. Scale bars, $25 \mu \mathrm{m}$. C, Hypoglossal motor neurons were counted in both Wistar rats (open circles) and C57BL/6 mice (filled circles). The percentage ratio of surviving motor neurons on the operated side compared with that on the control side was calculated. Each point shows the mean \pm SD $(n=8 ; p<0.01$ compared with the result of Wistar rat; $t$ test). $D$, Expression of representative survival-associated molecules $7 \mathrm{~d}$ after axotomy was examined by in situ hybridization. Arrows indicate an increase in mRNA on the operated side (right side). ERK1, Extracellular signal-regulated kinase 1.E, Expression of p53-dependent transactivated genes $7 \mathrm{~d}$ after axotomy. Scale bars:D, E, top, $1.3 \mathrm{~mm}$; bottom, 0.8 $\mathrm{mm}$. F, Proteins extracted from control (c) and operated (0) hypoglossal nuclei of mice $7 \mathrm{~d}$ after axotomy were subjected to Western blot analysis using polyclonal anti-Noxa and anti-GAPDH antibodies. 


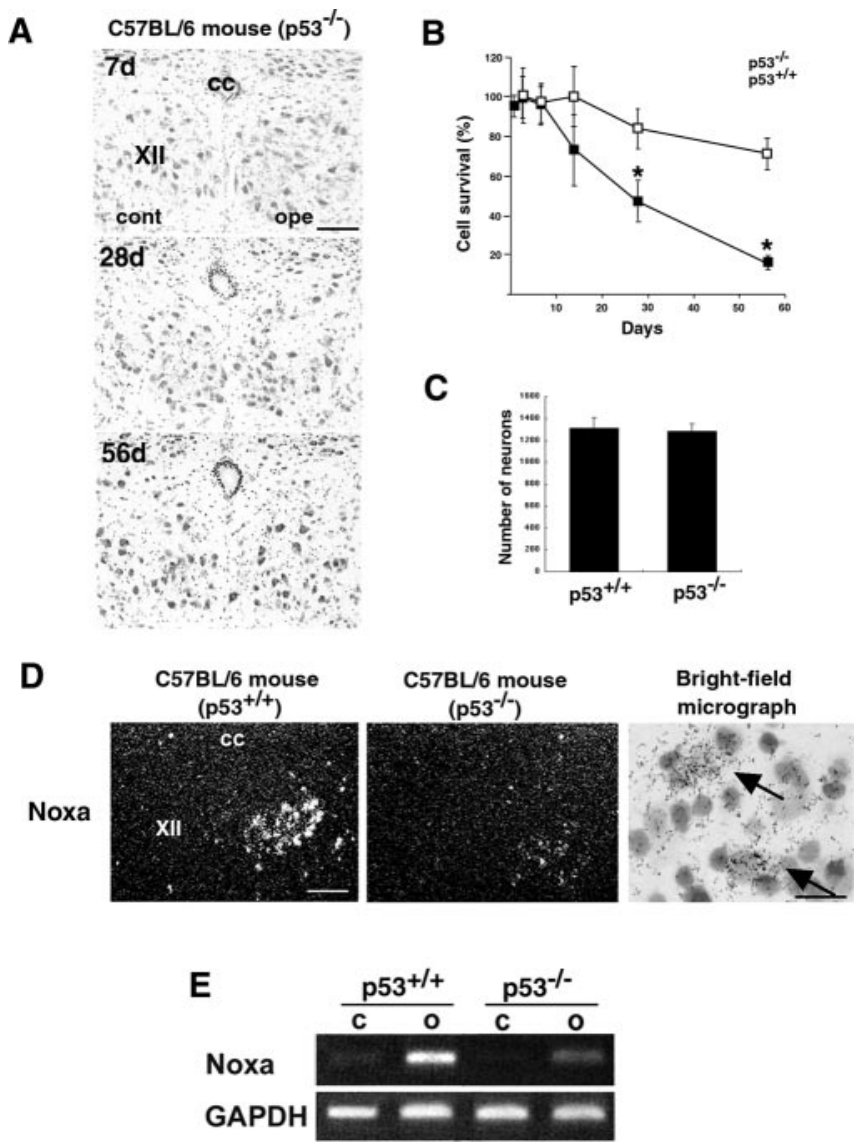

Figure 2. Motor neuron death of mice was associated with p53-dependent Noxa expression. $A$, p53 deficiency in mice ( $\mathrm{p} 53^{-1-}$ ) effectively prevented axotomy-induced cell death. Scale bar, $50 \mu \mathrm{m} . \mathrm{B}, \mathrm{p} 53$-deficient mice (p53 ${ }^{-1-}$, open squares) were rescued from motor neuron death compared with wild-type mice ( $\mathrm{p} 53^{+/+}$, closed squares) after nerve injury. The percentage ratio of surviving motor neurons on the operated side (right side) compared with that on the control side (left side) was calculated. Each point shows the mean \pm SD $(n=8 ; p<0.01$ compared with the result of $p 53$-deficient mouse; $t$ test). C, Number of neurons in hypoglossal nuclei (uninjured) from $\mathrm{p} 53^{+/+}$and $\mathrm{p} 53^{-/-}$mice. Values represent means $\pm \mathrm{SD}(n=6) . \mathrm{D}$, Emulsion autoradiography of in situ hybridization showed that Noxa mRNA was more markedly increased on the operated side in wild-type mice than in p53-deficient mice. Scale bar, $50 \mu \mathrm{m}$. The right panel shows a bright-field micrograph of the injured side, in which the silver grain of Noxa mRNA signal accumulated in large-sized injured motor neurons (arrows). Scale bar, 25 $\mu \mathrm{m}$. E, RT-PCR analysis of Noxa expression in control (c) and operated (0) hypoglossal nuclei obtained from wild-type $\left(\mathrm{p} 53^{+/+}\right.$) and $\mathrm{p} 53$-deficient $\left(\mathrm{p} 53^{-/-}\right)$mice. Expression of GAPDH was used as an internal control. Consistent with in situ hybridization data, the expression of Noxa mRNA was suppressed in p53-deficient $\left(p 53^{-1-}\right)$ mice.

mice. In situ hybridization revealed that Noxa expression was suppressed in injured motor neurons of p53-deficient mice compared with those of wild-type mice (Fig. 2D). Semiquantitative RT-PCR using control and operated hypoglossal nuclei also confirmed that Noxa expression was suppressed in p53-deficient mice after axotomy (Fig. 2E). These results clarified that Noxa expression is indeed regulated by $\mathrm{p} 53$ in injured motor neurons of adult mice. Slight but significant expression of Noxa mRNA was observed in nerve-injured motor neurons of p53-deficient mice (Fig. $2 D, E$ ), suggesting that p53-independent expression of Noxa exists to a minor extent. Nevertheless, the implication of p53 is significant in nerve injury-induced motor neuron death in the adult mouse, and a p53 target gene, Noxa, could be involved in this system.

To further clarify the consequence of Noxa expression in injured motor neurons, Noxa-deficient and littermate control mice
A
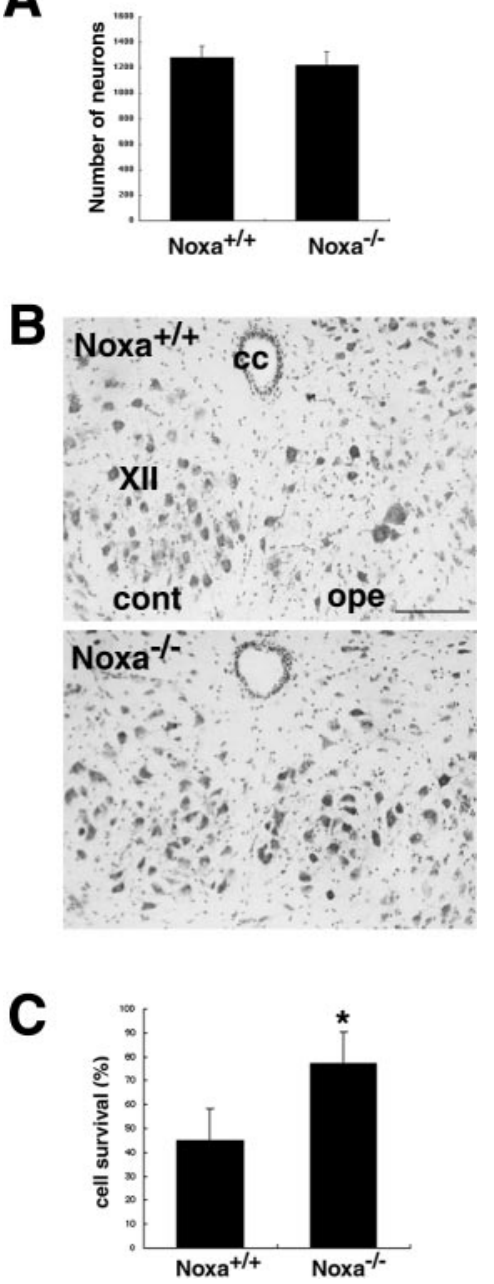

Figure 3. Noxa-deficient mice showed rescue from motor neuron death. $A$, Number of neurons in hypoglossal nuclei (uninjured) from littermate control (Noxa ${ }^{+/+}$) and Noxa-deficient $\left(\right.$ Noxa $\left.^{-l-}\right)$ mice. Values represent means $\pm S D(n=6)$. B, Thionine staining of hypoglossal motor neurons $35 \mathrm{~d}$ after hypoglossal nerve injury in Noxa ${ }^{+1+}$ and Noxa ${ }^{-1-}$ mice. Scale bar, $50 \mu \mathrm{m}$. C, Survival of motor neurons from Noxa ${ }^{+/+}$and Noxa ${ }^{-/-}$mice $35 \mathrm{~d}$ after axotomy. Results represent the percentage ratio of surviving motor neurons on the operated side compared with those on the contralateral side. Noxa ${ }^{+/+}(n=10)$ and Noxa ${ }^{-1-}(n=9)$ were significantly different $\left({ }^{*} p<0.01 ; t\right.$ test $)$.

underwent hypoglossal axotomy and were examined 5 weeks later. We confirmed that the number of uninjured motor neurons was similar in Noxa-deficient and wild-type mice (Fig. $3 A$ ). At 5 weeks after axotomy, the number of neurons was reduced by $\sim 45 \%$ in wild-type mice when compared with the uninjured side of the same mice (Fig. 3B,C). In contrast, the number of surviving neurons was significantly higher in Noxa-deficient mice $(\sim 80 \%)$.

Noxa is a prominent BH3-only proapoptotic factor expressed in nerve-injured mouse motor neurons

Noxa is one of the $\mathrm{BH} 3$-only proteins, which have been proposed to act upstream of mitochondria to regulate caspase activation. Therefore, we examined the expression of other BH3-only proteins, such as DP5, Bim, Bid, and Blk, after nerve injury. Among those examined, DP5, Bim, Blk, and Bid were slightly upregulated after nerve injury both in the rat and mouse. Among those examined, Noxa expression was the most notable in injured motor neurons of the mouse, whereas it was hardly detected in the rat 
(Fig. 4A). It should be emphasized that another p53 target gene, Puma, did not show any detectable signal in both the rat and mouse after axotomy. Semiquantitative RT-PCR analysis confirmed that a fourfold increase in Noxa mRNA was induced after nerve injury, although other $\mathrm{BH} 3$ only proteins showed an approximately twofold increase in mice (Fig. $4 B, C$ ).

\section{Discussion}

The present study revealed that slow progressive death of adult mouse motor neurons after axotomy is primarily p53 dependent and that a p53 target gene, Noxa, is a crucial executor in p53-dependent neuronal death. Because expression of p53 target genes such as $\mathrm{p} 21^{\mathrm{WAF} 1}, \mathrm{MDM} 2$, and Bax was equally observed in both the rat and mouse after nerve injury, p53 activation is apparent in both the rat and mouse. However, motor neuron death occurs only in the mouse. The major difference is the exceptional upregulation of Noxa in the mouse, and this might affect the balance between proapoptotic and prosurvival molecules such as $\mathrm{BH} 3$-only proteins and Bcl-2 family members. Because the balance is not severely disrupted in adult mouse motor neurons, axotomy-induced motor neuron death may progress slowly compared with that observed in the neonatal rat and mouse, in which expression of many prosurvival molecules is suppressed (Honma et al., 2002). In this respect, Noxa expression would be highly responsible for determining the fate of injured motor neurons in the adult mouse.

The balance between proapoptotic and prosurvival molecules can be disturbed after nerve injury. For instance, Bax knock-out, $\mathrm{Bcl}-2$ overexpression, or Bcl-XL overexpression succeeded in rescuing motor neurons from axotomy-induced death in vivo (Farlie et al., 1995; Deckwerth et al., 1996; Parsadanian et al., 1998). However, Bax can only execute cells in which essential initiators of cell death, such as $\mathrm{BH} 3$-only proteins, have been activated in response to stimuli, because newborn Bax transgenic mice did not show death of motor neurons after sciatic nerve axotomy (Bernard et al., 1998). One of the BH3-only protein members, Bim, was proved to accelerate death of sensory and autonomic ganglion neurons after NGF deprivation and nerve injury (Putcha et al., 2001; Whitfield et al., 2001; Napankangas et al., 2003). Similarly, mice deficient in DP5, another BH3-only member, were protected against nerve-injured motor neuron death after hypoglossal nerve injury, and SCG neurons were against delayed death by NGF deprivation (Imaizumi et al., 2004). It is possible that there might be cell-specific and/or stimulus-specific expression of $\mathrm{BH} 3$-only protein species, and thus, it would be intriguing to know which $\mathrm{BH} 3$-only protein participates in determining the fate of nerve-injured neurons. In injured motor neurons of the adult mouse, Noxa seemed to comprise a large proportion of $\mathrm{BH} 3$-only protein family members and to be enough to change the balance. Considering that p53 promotes cell death mainly through transcriptional activation, it can be concluded that Noxa is a crucial mediator of p53-dependent death. In con- trast, Puma, which was also identified as a p53-inducible gene, could not be detected in axotomized motor neurons of mice and rats, suggesting that Puma has a proapoptotic function in different types of neuronal death, such as ischemic death (Reimertz et al., 2003). However, additional regulatory mechanisms underlying Noxa expression might be also involved in vivo. Several findings suggest that E2F1 and HIF1 $\alpha$ also induce expression of Noxa, independent of p53 (Reimertz et al., 2003; Kim et al., 2004). Indeed, p53-deficient mice do not show absolutely abolished expression of Noxa after hypoglossal axotomy. Alternatively, another p53 family member, p73, which shares the same binding site as p53, might be involved.

In this study, the functional consequence of Noxa in injured motor neurons was clarified using Noxa-deficient mice. Noxadeficient mice showed significant survival of axotomized motor neurons. However, Noxa knock-out mice showed slightly less protection against nerve injury-induced death than those with p53 deficiency, suggesting the possible existence of additional p53-dependent death pathways. Recent reports support the idea that p53 has cytoplasmic and transcription-independent functions in promoting apoptosis (Chipuk et al., 2003; Mihara et al., 2003). In this case, p53 protein directly interacts with Bcl-XL with higher affinity, and such binding can release $\mathrm{BH} 3$-only protein from the Bcl-XL/BH3 protein complex. Thereafter, free $\mathrm{BH} 3-$ only protein might accelerate the Bax-dependent cell death pathway. Noxa-deficient mice could not show inhibition of such posttranscriptional activity of $\mathrm{p} 53$. In addition to p53-dependent $\mathrm{BH} 3$-only proteins, p53-independent $\mathrm{BH} 3$-only proteins are 
likely to be implicated. In fact, significant rescue activity was also observed in another $\mathrm{BH} 3$-only protein, DP5-deficient mouse (Imaizumi et al., 2004). It is therefore likely that this death program relied on redundant activity of more than one BH3-only protein. In the absence of Noxa, other $\mathrm{BH} 3$-only proteins are transcriptionally regulated by $\mathrm{p} 53, \mathrm{E} 2 \mathrm{~F} 1$ and $\mathrm{HIF} 1 \alpha$, and posttranscriptionally activated by signaling such as the c-Jun $\mathrm{N}$-terminal kinase cascade. Loss of one $\mathrm{BH} 3$-only protein might be insufficient to rescue injured neurons completely (Imaizumi et al., 2004). Nevertheless, it is now conceivable that p53 could be a pivotal molecule as an intracellular death signal generator in nerve-injured motor neurons of the adult mouse. Noxa could function as a main executor of p53-dependent cell death seen in injured motor neurons of the adult mouse.

\section{References}

Abercrombie M (1946) Estimation of nuclear population from microtome sections. Anat Rec 94:239-247.

Baptiste N, Prives C (2004) p53 in the cytoplasm: a question of overkill? Cell 116:487-489.

Bernard R, Dieni S, Rees S, Bernard O (1998) Physiological and induced neuronal death are not affected in NSE-bax transgenic mice. J Neurosci Res 52:247-259.

Chipuk JE, Maurer U, Green DR, Schuler M (2003) Pharmacologic activation of p53 elicits Bax-dependent apoptosis in the absence of transcription. Cancer Cell 4:371-381.

Clarke PG, Oppenheim RW (1995) Neuron death in vertebrate development: in vivo methods. Methods Cell Biol 46:277-321.

Deckwerth TL, Elliott JL, Knudson CM, Johnson EMJ, Snider WD, Korsmeyer SJ (1996) BAX is required for neuronal death after trophic factor deprivation and during development. Neuron 17:401-411.

Farlie PG, Dringen R, Rees SM, Kannourakis G, Bernard O (1995) bcl-2 transgene expression can protect neurons against developmental and induced cell death. Proc Natl Acad Sci USA 92:4397-4401.

Honma M, Namikawa K, Mansur K, Iwata T, Mori N, Iizuka H, Kiyama H (2002) Developmental alteration of nerve injury induced glial cell linederived neurotrophic factor (GDNF) receptor expression is crucial for the determination of injured motoneuron fate. J Neurochem 82:961-975.

Imaizumi K, Benito A, Kiryu-Seo S, Gonzalez V, Inohara N, Leiberman AP, Kiyama H, Nunez G (2004) Critical role for DP5/Harakiri, a Bcl-2 homology domain 3-only Bcl-2 family member, in axotomy-induced neuronal cell death. J Neurosci 24:3721-3725.

Kim JY, Ahn HJ, Ryu JH, Suk K, Park JH (2004) BH3-only protein Noxa is a mediator of hypoxic cell death induced by hypoxia-inducible factor $1\{$ alpha\}. J Exp Med 199:113-124.

Kiryu S, Yao GL, Morita N, Kato H, Kiyama H (1995) Nerve injury enhances rat neuronal glutamate transporter expression: identification by differential display PCR. J Neurosci 15:7872-7878.

Martin LJ, Liu Z (2002) Injury-induced spinal motor neuron apoptosis is preceded by DNA single-strand breaks and is p53- and Bax-dependent. J Neurobiol 50:181-197.

Mihara M, Erster S, Zaika A, Petrenko O, Chittenden T, Pancoska P, Moll UM (2003) p53 has a direct apoptogenic role at the mitochondria. Mol Cell 11:577-590.

Miller FD, Pozniak CD, Walsh GS (2000) Neuronal life and death: an essential role for the p53 family. Cell Death Differ 7:880-888.

Miyashita T, Reed JC (1995) Tumor suppressor p53 is a direct transcriptional activator of the human bax gene. Cell 80:293-299.

Morrison RS, Kinoshita Y (2000) The role of p53 in neuronal cell death. Cell Death Differ 7:868-879.

Nakano K, Vousden KH (2001) PUMA, a novel proapoptotic gene, is induced by p53. Mol Cell 7:683-694.

Napankangas U, Lindqvist N, Lindholm D, Hallbook F (2003) Rat retinal ganglion cells upregulate the pro-apoptotic $\mathrm{BH} 3$-only protein Bim after optic nerve transection. Brain Res Mol Brain Res 120:30-37.

Oda E, Ohki R, Murasawa H, Nemoto J, Shibue T, Yamashita T, Tokino T, Taniguchi T, Tanaka N (2000) Noxa, a BH3-only member of the Bcl-2 family and candidate mediator of p53-induced apoptosis. Science 288:1053-1058.

Parsadanian AS, Cheng Y, Keller-Peck CR, Holtzman DM, Snider WD (1998) Bcl-xL is an antiapoptotic regulator for postnatal CNS neurons. J Neurosci 18:1009-1019.

Polyak K, Xia Y, Zweier JL, Kinzler KW, Vogelstein B (1997) A model for p53-induced apoptosis. Nature 389:300-305.

Putcha GV, Moulder KL, Golden JP, Bouillet P, Adams JA, Strasser A, Johnson EM (2001) Induction of BIM, a proapoptotic BH3-only BCL-2 family member, is critical for neuronal apoptosis. Neuron 29:615-628.

Reimertz C, Kogel D, Rami A, Chittenden T, Prehn JH (2003) Gene expression during ER stress-induced apoptosis in neurons: induction of the $\mathrm{BH} 3$-only protein Bbc3/PUMA and activation of the mitochondrial apoptosis pathway. J Cell Biol 162:587-597.

Seo YW, Shin JN, Ko KH, Cha JH, Park JY, Lee BR, Yun CW, Kim YM, Seol DW, Kim DW, Yin XM, Kim TH (2003) The molecular mechanism of Noxa-induced mitochondrial dysfunction in p53-mediated cell death. J Biol Chem 278:48292-48299.

Shibue T, Takeda K, Oda E, Tanaka H, Murasawa H, Takaoka A, Morishita Y, Akira S, Taniguchi T, Tanaka N (2003) Integral role of Noxa in p53mediated apoptotic response. Genes Dev 17:2233-2238.

Snider WD, Elliott JL, Yan Q (1992) Axotomy-induced neuronal death during development. J Neurobiol 23:1231-1246.

Tanabe K, Nakagomi S, Kiryu-Seo S, Namikawa K, Imai Y, Ochi T, Tohyama M, Kiyama H (1999) Expressed-sequence-tag approach to identify differentially expressed genes following peripheral nerve axotomy. Brain Res Mol Brain Res 64:34-40.

Vousden KH, Lu X (2002) Live or let die: the cell's response to p53. Nat Rev Cancer 2:594-604.

Whitfield J, Neame SJ, Paquet L, Bernard O, Ham J (2001) Dominantnegative c-Jun promotes neuronal survival by reducing BIM expression and inhibiting mitochondrial cytochrome $c$ release. Neuron 29:629-643. 